\title{
Factors Influencing Real Estate Agents Selection: A Survey of Real Estate Customers in Kumasi Metropolis, Ghana
}

\author{
Owusu Alfred ${ }^{1}$, Anthony Kofi Badu², Nicholas Oppong Mensah ${ }^{3}$ \\ ${ }^{1}$ School of Business and Management Studies, Kumasi Polytechnic, Kumasi, Ghana \\ ${ }^{2}$ Department of Communication Design, Kwame Nkrumah University of Science and Technology, Kumasi - Ghana West Africa \\ ${ }^{3}$ Institute of Distance and Continue Education, Kwame Nkrumah University of Science and Technology, Kumasi - Ghana West Africa \\ Email address: \\ Alfredowusu76@yahoo.com (O. Alfred),kbadu70@yahoo.com (A. K. Badu),nicoppmens@yahoo.com (N. O. Mensah)
}

\section{To cite this article:}

Owusu Alfred, Anthony Kofi Badu, Nicholas Oppong Mensah. Factors Influencing Real Estate Agents Selection: A Survey of Real Estate Customers in Kumasi Metropolis, Ghana. Journal of Investment and Management. Vol. 4, No. 2, 2015, pp. 68-72.

doi: $10.11648 /$ j.jim.20150402.12

\begin{abstract}
Real estate is a special type of asset that almost everyone desire to own. It is a complex and highly differentiated asset, with no two units precisely identical in all respects. Real estate investment involves huge sum of money often beyond the reach of a single individual. For most estate owners, real estate is probably their single largest channel investment. It is therefore necessary that one makes the right choice on whom to handle ones single largest financial investment. This study attempt to investigate into factors that real estate customers consider in selecting their estate agents in Kumasi Metropolis, Ghana for the purpose of creating better customer satisfaction in real estate agency market. The data collection instrument adopted for this study was self-administered questionnaires. The study sample consisted of two hundred and three (203) real estate consumers in Kumasi metropolis. A survey of 203 real estate consumers revealed the factors influencing the selection of real estate agents in the study area. The study found out that real estate consumers are mostly concern about agent's reputation when deciding on the choice of whom to handle their probably single largest investment. The study also found that 75 representing $37 \%$ of the study population employs the services of real estate agents in order to maximize returns on their investment.
\end{abstract}

Keywords: Real Estate Consumers, Consumers' Satisfaction, Consumers’ Perception, Service Quality

\section{Introduction}

Real estate has also been described as one of the basic necessity of life. Most people need homes either as a freeholder or as a leaseholder. when individuals are in search of a house to buy or lease, estate agent can help to provide up-todate information regarding prices, mode of financing, terms and conditions of competing properties, and information about the property market in general. As a result, this makes it more likely that a buyer will find a satisfactory match much earlier in the search process. Suffice to say, an estate agent may be needed at least one in a life time.

Real estate agents obviously function as middleman and play a facilitating role of bringing buyers and sellers together. They facilitate the exchange of information between people in search of landed properties and estate owners.

For these reasons, it was difficult for both buyers and sellers to know whether a price offered is the best price they can obtain in a transaction or even a fairly good price. To overcome this lack of information base for assessing a single offer, buyers must have access to many real estate units offered for sale, and sellers to many potential buyers. According to Khadduri and Pusanov (1993), real estate agents can help to obtain this information for both buyers and sellers, thereby making it possible to lower transaction cost by lowering information search cost in order to market prices.

Real estate has also been described as a capital intensive business. It has been traditionally regarded as a lumpy and illiquid investment Levinard and lex (2010). This is because real estate investment requires huge capital outlay which is often beyond the capacity of the medium and low income groups. Most estate owners are therefore debtors to banks, cooperative societies or other financial institutions. It is therefore necessary that one makes the right choice about who to handle what probably is ones single largest financial investment (Kurtus, 2007).

The choice of real estate agent to handle ones investment 
will probably determine the profitability of that investment. According to Richardson (2005), home buyers and sellers trust that agents will play a vital role in the purchase or sale of their most important financial investment. They also trust their agents with information about their properties, financial qualifications and purchasing/selling intention. Agents in return must take reasonable steps to protect their client's information and satisfy them. When customer's are satisfied or over satisfied, it may translate into increased profits for both parties and help in ensuring efficiency and sustainability for the real estate agency market as a whole because the customer will stay and even make a word of mouth recommendation for the agent (Kurtus, 2007).

It is in the light of this, that this study attempts to investigate factors that prospective buyers or customers consider in selecting of real estate agents.

This paper is divided into eight sections; the introduction, statement of the problem is followed by the review of related literature. Study area is followed by the literature review and the next section is methodology and data analysis. The last section deals with the discussion of results, conclusion and recommendation.

\section{Statement of Research Problem}

Many authors have written extensively on determinates of real estate selection from different angles and countries. None of these studies looked at it from the Ghanaian or the Kumasi metropolis context. All the studies were skewed towards service quality, property prices, agent and vendor time etc. in the case of Linda .L Johnson work on Service quality determinates and effectiveness in the real estate brokerage Industry in the US the study explore service quality in the US real estate market. Elizabeth Hemphill paper titled factors affecting real estate broker selection: what really counts? The study Explores agent sales representation in real estate property. The paper also examines the influence of time to both agent and vendor alike. Finally, Anderson .M Kiggie in his paper titled factors real estate property prices a survey of real estates in Meru Kenya. The paper investigates factors at play in determining real estate property prices in Meru Municipality in Kenya. From the above author's paper, it is clear that it's skewed towards a particular end and has therefore resulted in a gap which this study intends to fill.

\section{Review of Literature}

Traditionally a real estate agent had the responsibility of marketing property for sale or lease. When a consumer uses an estate agent, he/she is likely to get a far better result than conducting a search on his/her own. According to Stewart (2009), "understanding the perspective of the consumer is not a simple task. Consumer's perspective of service quality differs from one another and each takes a different approach to the evaluation of how satisfied they are. It is difficult to know the exact factors that influence individual's choice.
However, there are some authors that have investigated into this issue and they came up with a number of factors.

Johnson et al. (1988) in an exhaustive North Carolina study found out that 'selling ability', 'competence', 'integrity', 'market knowledge' and 'ability to understand client needs' are very important factors real estate consumers consider in their choice of real estate agent. The authors established that the individual agent is more important than the firm in the selection of an agency. Pastiroff, (2004) noted that range of services, fee structure/levels, consultant's network, track record and market knowledge are important factors that real estate consumers consider when deciding the choice of real estate agent. He found out that some factors are more important than others. According to the author, market knowledge was the most important factor, followed by track record and then consultant's network. Pastiroff (2004) further investigated into reasons for using the services of estate agents. He found out that the main reason why real estate customers employ the services of an estate agent was to 'concentrate on core businesses'. The vast majority of the real estate customers that were interviewed by the author got their real estate agent through established relationship.

Michael et al (1990) examined factors that affect real estate sales staff performance from sixteen firms of various sizes in different residential markets. They identified five variables affecting real estate sales staff performance. It was reasoned that if these variables could affect performance, it could also influence client's decision when selecting real estate sales staff. These variables included gender, hours worked per week, amount of formal education, work satisfaction, and reputation of the firm.

Nagpal (2009) compared choosing a real estate agent to choosing a doctor. According to the author, if one do not choose the right real estate agent for ones job, the property transaction is unlikely to see the light of the day. A good real estate agent would open a number of good opportunities for his/her customers. Nagpal (2009) identified some soft qualities of a reliable estate agent. An estate agent should be easy to talk to and smart to understand his/her client's question; flexible to work according to the time schedule; a computer savvy; quickly respond to any queries or doubts and well networked with other estate agents. The presence or absence of these qualities in an estate agent could determine the quality and quantity of clients that would patronize the agent.

Leona and Lucy (2002), Brits and Mortar (2006), Mahida (2007), RSS (2007), Bhattacharya (2008) and Pretty (2008), lighted some important questions to ask an estate agent before dealing with them. Some of these questions are: number of years in the business; agents' firm's name and reputation; agents' availability; agents' area(s) of specialization; number of transactions involved in; membership professional body; likely duration of search; agents' marketing plans and programme; number of clients currently working with etc.

Khadduri and Pusanov (1993) observed that the sales and purchases of real estate occur relatively infrequently and 
usually an individual is involved in only a few such transactions in a life time.

According to the authors, these questions may help one decide or locate an agent that is appropriate for ones needs when responses to these questions have been carefully and objectively evaluated. This study however employ some of these variables that has been established in literature to assess the property market in order to determine the factors that influence real estate consumers in their choice of real estate agent in Kumasi metropolis.

\section{Study Area}

The study area for this research work is Kumasi Metropolis. Ideally, the study should consider the whole country but for manageability and thorough analysis, the study was restricted to this area. The restriction to Kumasi metropolis was informed by the fact that the metropolis is one of the most important commercial cities as the volume of economic activity in metropolitan Kumasi exceeds that of all capitals or towns in the country. Also time, financial constraints, in-depth knowledge of the market and been able to speak the local language was some of the good reasons why the study area was chosen. The membership directory of the Ghana Institution of Estate Surveyors and Values showed that approximately $54 \%$ of estate surveying firms in Ghana is either based or has their branch in Kumasi metropolis.

\section{Methodology}

The study was conducted in Kumasi metropolis. The focus group for this research work was mainly real estate service consumers. It was used to solicit views from the selected groups the groups were mainly three (3), home owners group, home buyers group and tenants group were asked different set of questions about what influence them in selecting estate agents. 234 estate surveying firms were randomly selected representing $50 \%$ of the total number of estate surveying firms in the study area. This is believed to be a fair representation of the entire population. From each estate surveying firm, two (2) service consumers were purposively selected given rise to a total number of 236 real estate service consumers. The study adopted self-administered questionnaire as its data collection instrument.

Each consumer was asked to complete a questionnaire. The questions focused on reasons why customers need the services of estate agents and how they got their present estate agent. More specifically, customers were asked to identify the factors they consider in their choice of real estate agent.

\section{Data Collection}

A total number of 236 questionnaires were administered to the survey sample but 207 questionnaires were retrieved. 4 responses were found unusable. Valid responses totaled 203, an $86 \%$ response rate which is relatively high despite the nature of the sample (professional people who are always busy, non-homogenous and not predisposed to complete a questionnaire). The author believed that the sample fairly represents the population surveyed.

\section{Results and Discussion}

Consumers were asked to complete a questionnaire relating to issues that motivated them to select their present real estate agents among other agents. The following are highlighted extracts from the results of the 2013 real estate consumer survey carried out in Kumasi metropolis, Ghana.

\subsection{Sample Characteristics of Participants}

The sample characteristics for real estate consumers that participated in the study are shown in Table 1 . The consumers consist of $77.3 \%$ male and $22.7 \%$ female. The relatively large number of male agents is not unexpected considering the strenuous nature of the work. The average consumer was between the ages of 36 - 50 years old and had an average annual income of over GH40, 000. 56.3\% of real estate consumers were married, $38.8 \%$ single and the remaining $4.9 \%$ divorced.

Table 1. Sample characteristics of participants.

\begin{tabular}{lll}
\hline Characteristics & Results & Percentage (\%) \\
\hline \multirow{4}{*}{ Age, years } & $<35$ & 59.1 \\
& $36-50$ & 34.0 \\
& $>50$ & 6.9 \\
Education & Graduate Degree & 46.8 \\
& Masters Degree & 37.9 \\
Sex & Others & 14.8 \\
& Male & 77.3 \\
Year of Experience & Female & 22.7 \\
& Mean & 10 years \\
& Single & 56.3 \\
& Divorced & 38.8 \\
& Civil Servant & 4.9 \\
Occupation & Self Employed & 56.2 \\
& Others & 34.5 \\
& $<$ GH $\notin 10,000.00$ & 9.3 \\
Annual Income & GH $\varnothing 10,000.00-$ GH $\varnothing 40,000.00$ & 22.7 \\
& $>$ GH $\varnothing 40,000.00$ & 51.7 \\
\hline
\end{tabular}

Source: Author's Field Survey (2014)

Characteristics of Real Estate Service Consumers (2014)

The 203 consumers comprising tenants, home owners and home buyers that were surveyed had an average length of 10 years experience in real estate related businesses. Majority of the consumers were civil servant and have a graduate degree as the highest level of education attained. From this outcome, it may be deduced that most of the consumers are qualified to know the importance of research and can be relied on to give reliable information. Therefore the credibility of the data is sustained and the information obtained actually reflects the view of real estate service consumers in the subject under 
study.

\subsection{Methods of Selecting Real Estate Agent}

Table 2 presents results to the question "How did you get your present real estate agent?" Of the total sample of real estate consumers, $39.9 \%$ indicated that they got their present real estate agent through established relationship, that is, they performed well in the first contact, and so they decided to keep the agent. $32.7 \%$ of the respondents indicated that their agents were recommended to them by friends, colleagues or business partners. $15.3 \%$ indicated that their present real estate agent was actively searched for having heard of the agent's performance and good reputation while only twentytwo (10.7\% of the sample) were approached by their present real estate agent. Three representing $1.5 \%$ of the sample specified other means through which they got their present estate agent; through advert and that they personally know the agent. From these results, it is evidenced that real estate consumers do not just pick any real estate agent on the street. They must have been that the agent performed well in the first contact or they heard a good report about the agent from family, friends etc that drives the selection of that particular real estate agent.

Table 2. Methods of selecting real estate agents.

\begin{tabular}{l|ll}
\hline Methods & Frequency & Percentage (\%) \\
\hline Established Relationship & 81 & 39.9 \\
They approached you & 22 & 10.7 \\
They were recommended & 66 & 32.7 \\
Actively Searched & 31 & 15.3 \\
Others & 3 & 1.5 \\
Total & 203 & 100.0 \\
\hline
\end{tabular}

Source: Authors' Field Survey (2013)

\subsection{Reasons for Using a Real Estate Agent}

Table 3. Reasons for using a real estate agent.

\begin{tabular}{lll}
\hline Parameters & Frequency & Percentage\% \\
\hline Cost Effective & 26 & 12.8 \\
Less Difficulties & 34 & 16.7 \\
To Maximize Returns & 75 & 37.0 \\
To Concentrate on Core Business & 68 & 33.55 \\
Total & 203 & 100.0 \\
\hline
\end{tabular}

Source: Authors' Field Survey (2014)

Table 3 documents the reasons why real estate consumers employ the service of an estate agent. The main reasons according to real estate consumers are to maximize returns on their investment and to concentrate on core business. This is supported by the findings of Pastiroff (2004) in his research on real estate consultancy which says there was a clear demand from client for more financially based real estate consultancy services, covering issues such as; taxation, financing options and indirect property investment.

The response "cost effective" means to minimize cost which from the findings is the least reason why a client decides to use an estate agent. The result indicated that the most important reason for using an estate agent is to maximize return that is to get the best possible result. Seventy-five representing $37 \%$ of the population attested to this fact. This might be due to the fact that real estate service consumers have realized that the costs of being involved in real estate related services are substantial and often result into a waste of time and resources. Majority of the respondents agreed that real estate agents know the best way to meet their need within the shortest possible time.

\subsection{Methods of Securing Customers}

Table 4 clearly gives real estate customers' responses on how real estate agents obtain instruction from their customers. The real estate consumers were asked if estate agents approach them in order to secure instruction for work. The options were "yes or no". The study revealed that larger percentage of the real estate consumers (precisely 59\%) were approached by real estate. The study found out that majority of real estate agent goes for scouting and in the process approach potential clients in order to secure work from them. This contravenes the rules and regulations for the practice of estate surveyors and valuers, Decree No. 24 of 1975 which states that "No estate surveyor and valuer shall solicit instructions for work in any manner whatsoever provided that this rule shall not apply in the case of a general information about the firm or organization in question and not related to canvassing for any specific job".

This pattern could possibly be due to the presence of many estate agent firms on the streets of Kumasi Metropolis and even other professionals practising real estate related businesses. All these strive for survival. It was assumed that if they stay in their offices, they may not get as much customers as they have. Also, as they go out to source for properties, they create awareness to the general public on what real estate is all about and the benefits of employing the services of real estate agents either in search of a property or for management purposes. The study also found that despite the real estate consumers were approached by estate agents, this does not automatically mean that they will secure instruction to work. There are still certain characteristics that attract real estate consumers to a particular agent.

Table 4. Methods of securing customers.

\begin{tabular}{lll}
\hline Options & Frequency & Percentage\% \\
\hline Approached & 120 & 59 \\
Not Approached & 83 & 41 \\
Total & 203 & 100.0 \\
\hline
\end{tabular}

Source: Authors' Field Survey (2013)

\subsection{Factors Determining the Choice of Real Estate Agents}

Table 5 shows the responses of real estate consumers on factors they considered important when deciding on which real estate agent to choose. The respondents were asked to give a simple ranking of five factors extracted from literature on real estate agency. These factors are fee structure/levels, age of firm, agent's reputation, manner of approach, agent/consumer's relationship, range of services, agents' 
consultancy network and others which they are expected to specify.

Table 5. Factors determining the choice of real estate agents.

\begin{tabular}{ll}
\hline Options & Mean Scores \\
\hline Fee Structure/levels & 2.6 \\
Age of Firm & 1.2 \\
Agent's Reputation & 3.2 \\
Manner of Approach & 2.3 \\
Agent/Consumer Relationship & 1.7 \\
Range of Services & 1.4 \\
Agents' Consultancy Network & 3.0 \\
\hline
\end{tabular}

Source: Authors' Field Survey (2014)

4=Extremely Important

$3=$ Important

$2=$ Slightly Important

$1=$ Not important

The results clearly showed that some factors are more important than others.

Agent's reputation was the most important factor and was rated as either; "extremely important" or "important" by almost all respondents. Agent's reputation has to do with the opinion that people have about the agent based on what has happened in the past. We have heard clients saying "Agent $Y$ has a good record" purely on the basis that Agent $\mathrm{Y}$ has always performed well.

Agents' consultancy network was the second most important factor, followed by fee structure, manner of approach and lastly age of firm. This means that the age of the firm does not really affect the performance of the agents. It was also observed that the individual agent and not the firm/company itself that is more important to real estate service consumers. This supported the finding of Johnson et al. (1988) that the relationship consumers have with their agent is very close compared with the firm/company that employed the agent.

The last finding of this study concerned the question whether clients would like to retain their agents and if they could recommend their present agents to their friends or relatives. Table 6 showed the details of the result.

Table 6. Overall perception of real estate agents.

\begin{tabular}{llll}
\hline Parameters & No & Undecided & Yes \\
\hline $\begin{array}{l}\text { Possibility of repeat business } \\
\text { Possibility of recommending }\end{array}$ & $5.9 \%(12)$ & $9.9 \%(20)$ & $84.2 \%(171)$ \\
$\begin{array}{l}\text { Agents to } \\
\text { others }\end{array}$ & $10.3 \%(21)$ & $9.9 \%(20)$ & $79.8 \%(162)$ \\
\hline
\end{tabular}

Source: Authors' Field Survey (2014)

The result as condensed in table 6.0 above clearly suggested that majority of the clients would like to carry out repeat businesses with their real estate agent and also recommend them to their friends or relatives. This indicated that the consumers are to some extent satisfied with the performance of their real estate agents. It should however be noted that the results of this study may or may not be generalized to other study areas.

\section{Conclusion/Recommendation}

The study attempts to investigate into important factors influencing the choice of real estate agent in Kumasi metropolis from real estate consumer's perspective. The study found out that agent's reputation was the most important factor real estate consumers consider in selecting estate agent. It was also found that most real estate consumers got their present real estate agent through established relationship. This relationship must have been created in their first contact. This implies that when agents perform well in their first contact with their customer, the customers are likely to come back and possibly introduce their agents to others. The study recommended that agents should try and build reputation and relationships because these were the issues that emerge hence policies aimed at building reputations and taking the customers up the relationship must be pursued to create a good first impression as there may be no other chance to make amendment.

\section{References}

[1] Department of Real Estate, A Consumer's Guide, Phoenix, Arizona, $\quad$ pp. $\quad 10 \quad-\quad 16$. http://ezinearticles.comhttp://www.school-forchampions.com/.

[2] Johnson, J.M., Nourse, H.O., Day, E. (1988). Factors Related to the Selection of a Real Estate Agency or Agent, Journal of Real Estate Res., 3(2), 109-118.

[3] Khadduri, J., Pusanov, A. (1993). Beginnings of Real Estate Brokerage in Moscow, Housing Policy Debate., 4(4), 627-646.

[4] Kurtus, R. (2007).Using Location for a Competitive Advantage in Business, from.

[5] Michae, A.A., Michele, K.K., Ellen, F.J. (1990). Factors Influencing Real Estate Brokerage.

[6] Moyinola \& Olatoye; (2011)This is an Open Access article distributed under the terms of the Creative Commons Attribution License (http://creativecommons.org/licenses/by/3.0), which permits unrestricted use, distribution, and reproduction in any medium, provided the original work is properly cited.

[7] Nagpal, L. (2009). Factors Influencing Selection of a Real Estate Agent., from.

[8] Pastiroff, A. (2004). The Swedish Real Estate Consultancy Market - Status and Trends, Master of Science Thesis, Department of Infrastructure, Division of Building and Real Estate Economics, Royal Institute of Technology, Stockholm.

[9] Richardson, E. (2005). Buying Real Estate in Mexico, A Publication of the Arizona.

[10] Sales Staff Performance, Journal of Real Estate Research, America Real Estate Society, 5(2), 265 -276.

[11] Stewart, A. (2009). Leisure: Universal Themes in Consumer Perceptions of Quality and Satisfaction from http://www.friendsofvista.org/articles. 